\title{
PROPHYLAXIS OF SYPHILIS BY LOCALLY APPLIED CHEMICALS. METHODS OF EXAMINATION, RESULTS, AND SUGGESTIONS FOR FURTHER EXPERIMENTAL RESEARCH
}

By WERNER WORMS, L.R.C.P., L.R.C.S.Ed., L.R.F.P.S.Glasg.

THE increased incidence of syphilis which accompanies war conditions makes it necessary to think again of all possible means of prevention. Among the available weapons individual local chemical prophylaxis is important although the results obtained by it have not been uniform either in practice or in experimental research.

In this paper, after giving a short, critical review of the locally applied chemical preparations that have been tested in the prophylaxis of syphilis, methods of testing these preparations and the results attained, I shall offer some suggestions for future research on this subject.

The most important question in all experimental work of this kind is how to test the value of a chemical preparation. It may be done in vitro, in vivo, or in both.

Examinations in vitro.- One method described by Schereschewsky was designed only for preliminary investigation. A drop of serum containing abundant and very motile $S$. pallida, from either a human or an animal syphilitic lesion, and an equal amount of the chemical preparation under test are placed on an absolutely clean slide at such a distance apart that when a perfectly clean coverglass is placed on both it causes them to mix under its middle, but leaves at one side the spirochetes untouched by the preparation; these spirochetes thus act as a control. The presence of the control spirochetes under the same coverglass is important because, apart from the influence of a chemical preparation, spirochetes may lose their motility owing to drying, anisotony, oxidation, illumination and changes of temperature. 


\section{PROPHYLAXIS OF SYPHILIS}

Only experiments therefore in which the control spirochetes remain motile during the whole time of observation can be used. This method was used for a great variety of preparations by Schereschewsky and Worms. Later Gauducheau, Esquier, and Bessemans, van Thielen and de Wilde examined also the influence of chemical prophylactic preparations on the motility of $S$. pallida in vitro but used techniques which differed in some respects; of these only Gauducheau's technique will be described later. In the experiments of Schereschewsky and Worms whereas the 40 per cent. quinine ointment of Schereschewsky immobilised the spirochetes immediately, the $33 \frac{1}{3}$ per cent. calomel ointment of Metchnikoff failed completely in this respect. Similarly in further experiments by myself a 30 per cent. calomel ointment in a base of benzoated lard and white wax under these conditions had no influence on S. pallida. Only Bessemans and co-workers saw a slight effect of the 33 per cent. calomel ointment in such conditions, and it was worse than that of the quinine ointment. Unfortunately the results of these in vitro examinations performed by Schereschewsky, Schereschewsky and Worms, Bessemans and co-workers did not at all correspond to those given by better and more reliable methods, and for these reasons the slide method of Schereschewsky is practically useless for testing chemical prophylactic agents.

Examinations in vivo.-A second test recommended by Schereschewsky is to observe the effect of applying the preparation to a syphilitic lesion (human or animal) rich in very motile spirochetes for twenty-four hours. At the end of this time the effect is tested by removing with a capillary pipette a drop of serum made to ooze from the superficial layers of the lesion by slight scarification and examining it by dark-ground-microscopy. This test was employed by Schereschewsky and Worms and later in a somewhat similar way by Esquier. It is a more severe test than one in vitro, if it requires that after application of the ointment for twenty-four hours only immobile spirochetes are to be encountered because here the spirochetes are not so defenceless as between the slide and the coverglass. In this method it was not intended to prove that the whole syphiloma should be sterilised, as some authors have thought, only that a locally applied prophylactic preparation should be able to kill the v.D. 
spirochetes in the superficial layers when these were exposed to its action for twenty-four hours. A disadvantage of this method, however, lies in the possibility that spirochetes from deeper layers may reach the superficial ones a short time before the examination; there is also the fallacy that even under normal conditions $S$. pallida may lose its motility without any evident external reason. It is surprising that, under these conditions also, whereas the quinine ointment of Schereschewsky was very active (Schereschewsky and Worms), the $33 \frac{1}{3}$ per cent. calomel ointment had no effect (Schereschewsky and Worms). The unreliability of the method is proved by this difference in the effect of the two ointments because, as will be explained later, whereas the quinine ointment was mostly a failure in the prevention of experimental rabbit syphilis in proper circumstances, the calomel ointment was rather successful.

The best method of testing a chemical prophylactic preparation is to observe its effect in the prevention of a syphilitic infection in man or a suitable animal.

As to experiments on man, I need not refer to Metchnikoff's successful experiment on the medical student, Maisonneuve, with calomel ointment. In criticising this experiment Esquier seems to have been quite right in pointing out that there was no strict evidence on the one hand that Maisonneuve was not already a syphilitic when it was performed or, on the other, that the inoculation did not result in a latent infection.

In the experiments on animals, prevention of the infection has been tried by applying the prophylactic disinfectant either before, or after, or both before and after inoculation with syphilitic material. Strictly speaking, all the measures carried out after inoculation are not prophylactic but abortive therapeutic measures.

Another method of testing is both in vitro and in vivo, that is to say, the inoculation material is mixed with the prophylactic preparation, and they are allowed to act on one another for some time, after which a suitable animal is inoculated with the mixture. Experiments by this method have been carried out by C. Siebert and, with modifications mentioned below, by Schereschewsky and Hügel on monkeys.

It was also on monkeys that the first experiments in vivo were carried out by Metchnikoff and Roux. The I 88 


\section{PROPHYLAXIS OF SYPHILIS}

region of the eyebrows of chimpanzees, baboons and macacus cynomolgus monkeys was inoculated with human syphilitic material, and various mercurial preparations ending with $33 \frac{1}{3}$ per cent. calomel ointment were applied to the inoculated areas. Some of the inoculated monkeys were not treated, being used as controls. These experiments are not, however, decisive, as at that time the possibility of a suppressed or latent infection was not properly excluded.

Schereschewsky tried to improve on this method by combining test and control experiment on the same monkey. He inoculated both eyebrows with human syphilitic material and applied the prophylactic preparation only to the region on the right of the middle line. In this method also the non-appearance of a primary sore on the treated area was regarded as a successful effect of the chemical. The method tried to overcome the error due to a difference in susceptibility between the test and control animals, but an obvious disadvantage of such a procedure is that it is impossible under it to state whether non-appearance of a lesion is due to prevention of infection or merely to suppression of signs.

In all these experiments the monkeys were inoculated by very strong methods, that is to say, the animals had to sustain injuries of such an intensity as practically never occur in human practice. It was, however, necessary in the monkey experiments in order to get as high a proportion of primary sores as possible. The use of monkeys for such experiments has the disadvantage that this experimental animal is much too expensive for a detailed examination of a prophylactic preparation on a broad basis, at least in Europe. The expense of monkeys limits the number of animals per experiment and the number of passages, and results in the use of human $S$. pallida which have not attained full virulence for these animals (Manteufel and Worms, I928). Quite another condition, however, would arise if it were possible that the infection could always be transmitted in them by copulation, as the testing conditions would then correspond more closely to the circumstances of human infection.

A new area for investigation of local chemical prophylaxis on animals began when Nichols and Walker in I923 successfully infected rabbits percutaneously (scrotI89 


\section{BRITISH JOURNAL OF VENEREAL DISEASES}

ally) with the Nichols pallida strain, which by this route gave positive results up to Ioo per cent. These results were confirmed by myself with the same strain, kindly sent to me when I was working in Berlin by Dr. Nichols. With Manteufel (I925), I found that other laboratory strains of $S$. pallida could be inoculated in the same (scrotal) way with the same percentage of positive takes.

As Brown and Pearce had shown that a latent infection in rabbits could easily be verified by a positive lymph gland transfer from such animals to healthy rabbits, it became possible to investigate if a rabbit which had been inoculated and afterwards treated by a local chemical preparation without showing signs had actually been protected from the infection or if only the primary sore had been suppressed. Nichols and Walker were the first investigators who made use of such a combined examination. Some of the animals were locally treated with the chemical preparation; the others served as controls. The treated animals were observed for three months, and if then any of them was still without a primary sore, an inguinal gland was removed for transfer to healthy animals. In my own experiments I did not follow strictly the technique described by Nichols and Walker. In the first place the period of observation was extended to eight months, because two of my animals which were apparently protected did not develop primary affections until four and five months after the inoculation. Secondly, if the lymph gland transfer of an apparently protected animal did not lead to the development of a syphilitic lesion in this animal, a lymph gland of this second animal was removed, and inoculated into a fresh normal rabbit. This procedure was very often used in these prophylactic experiments, after I had found that sometimes a latent infection could be detected only by a second passage by means of a lymph gland transfer.

In my researches respecting the distribution of $S$. pallida in the lymph glands of rabbits infected with experimental syphilis I had found that not all the lymph glands may be infected, a result which was also verified by second gland transfers. Therefore in three of the animals which had not shown any syphilitic changes after the inoculation and local prophylactic treatment, the inguinal, popliteal, axillary lymphnodes as well as brain, blood, liver, lungs, spleen, heart were inoculated

$$
\text { I90 }
$$




\section{PROPHYLAXIS OF SYPHILIS}

separately into a large series of animals; none yielded a positive result, as verified also by second gland transfers. The conclusion from these experiments is that, if an apparently protected animal does not show any syphilitic affection in a period of several months (five) and after that time a lymph gland transfer in two passages does not yield a positive result, such an animal is to be considered as having been really protected from the infection. It is, however, safer according to my experience concerning the distribution of $S$. pallida in the lymph glands of latent syphilitic rabbits to excise and transfer several lymph glands at a time, or alternatively if the animal can be sacrificed, to inoculate fresh rabbits with an emulsion of the internal organs, testes and several lymph glands. All negative results should be checked by second passages.

A very important point in these experiments which make use of the percutaneous (scrotal) route of inoculation is the way in which the mechanical injuries are done. Nichols and Walker made I5-20 superficial abrasions of the scrotal skin " by allowing a razor to glide lightly over the surface of an area of approximately I to $\mathrm{I} \cdot 5 \mathrm{~cm}$., bleeding being avoided as much as possible." About 0.05 c.c. of a spirochete suspension was placed on the scarified area and rubbed lightly with the sides of the capillary pipette. In my experiments the testicles of the rabbit were drawn into the scrotum and prevented from gliding back by applying a clamp to the spermatic cord. The scrotal skin made taut in this way was then scarified by a Pasteur glass capillary pipette. According to the degree of the injury the experiments gave different results, the greater the injury the less successful was a locally applied chemical preparation in preventing the infection. Injuries which normally occur in sexual intercourse will hardly ever be so severe as in the strong scarification experiments made on rabbits, but deep rhagades and fissures due to herpetic and other affections and those due to tears of the frenum may also occur in men, and a locally applied prophylactic preparation should always be tested for its ability to prevent an infection, whether the inoculation is by superficial or by deep scarification. I am convinced that the differences in the results of many investigators with the same preparation are to a great extent explained by the different

IgI 


\section{BRITISH JOURNAL OF VENEREAL DISEASES}

methods of inoculation. In this connection I mention again my own experiences in which I always saw worse results if I scarified deeply than if I made only superficial injuries before the inoculation. The same holds good for the time interval between the inoculation and the local prophylaxis. The same preparation was able to prevent at a longer interval after a superficial inoculation than after a deep one.

With the object of making the experimental conditions more similar to those existing in practice, especially in respect of hyperæmia, I made the following experiments. In nine rabbits the testes were drawn down and the scrotal skin kept taut over them as described above. To the scrotums of two rabbits a piece of cotton wool dipped in very hot physiological saline was applied for two minutes so that the skin was scalded; to the same part in the other seven was applied a piece of wool dipped in saline which was only at bloodheat. After short dabbing up with dry cotton wool I applied the spirochetal suspension to the scrotal skin thus prepared and let it dry in. I avoided rubbing in the spirochetal suspension as the relatively tender scrotal skin was very hyperæmic. One of the first two rabbits and three of the other seven served as controls. The result was that only the control animal of the first group developed a primary sore, while the corresponding animal which was treated with calomel ointment 20 minutes after the inoculation escaped infection (checked by lymph gland transfer in two passages). The three controls of the second series escaped infection (checked in the case of two of the animals by lymph gland transfers in two passages) so that the non-occurrence of pathological changes in the other four animals (checked in two rabbits by lymph gland transfers in one passage and in one rabbit by lymph gland transfer in two passages) cannot be counted as a successful prevention. The experiment shows that even a very virulent spirochete strain may penetrate the scrotal skin of the rabbits only after a certain degree of epithelial injury and that a correct evaluation of prophylactic preparations is rendered difficult if the methods of inoculation are too mild. On the other hand, if the local injury is too severe, no, or hardly any, prophylaxis may succeed. So Zurhelle, who scarified the scrotal skin rather deeply with one blade of 


\section{PROPHYLAXIS OF SYPHILIS}

a curved pair of scissors, got worse results than most of the other investigators, who used milder methods. When, however, Zurhelle tried to mitigate his method by performing the scarifications 24 hours before the inoculation he got only a small percentage of positive takes even in his control animals, so that this procedure does not seem suitable. His object in employing this method was to imitate conditions in nature when a healing lesion is exposed to contamination by syphilitic discharge.

Another method of testing chemical prophylactic preparations in experimental rabbit syphilis was introduced by Bessemans, de Wilde and van Thielen. They inoculated the uninjured conjunctival membranes of both eyes of rabbits with spirochetes (squeezing a piece of syphilitic tissue rich in spirochetes) and rubbing in the juice thus obtained by means of a little round glass rod. The eyes of some of the animals were treated with prophylactic agents, those of others were treated only with the vehicles of the preparations; the remainder of the animals served as controls. A very important feature of this method is that these authors were able to get roo per cent. takes in the control animals (keratitis syphilitica, 90 per cent.; latent infections, Io per cent.), though this method of inoculation seems to cause only slight injury. On the other hand, this method must be really a very mild test, as even the vehicles of Metchnikoff's, of Gauducheau's and of Schereschewsky's ointments prevented the infection by a purely mechanical action in the first hour after the inoculation.

A new way of testing prophylactic agents on experimental rabbit syphilis has been described by Mahoney. It consists " in exposure of the genital mucous membrane of the male rabbit by means of a tissue emulsion containing numerous virulent and always motile treponemata of a laboratory strain. The animal to be exposed is placed on an animal board and a small pledget of cotton saturated in the emulsion is carefully packed into the preputial sac and maintained in position by clamping the fur about the orifice with a hæmostat. At frequent intervals during the course of the exposure the clamp is removed and additional emulsion applied by means of a medicine dropper. In all manipulations care is exercised to avoid injuries to the soft tissues." After the exposure the prophylactic treatment is carried out. 
A disadvantage of this method is in the fact that the positive results do not often give rise to typical indurated chancres, but sometimes only to erythemata "which may progress to a definite sclerosis or may recede without further change." Other errors may arise through the presence in the test animals of a latent spontaneous spirochetosis due to $S$. cuniculi, which, as is known, is morphologically indistinguishable from $S$. pallida. In doubtful cases the author recommends that the suspected lesion be inoculated into the testes of another rabbit. If it is due to S. cuniculi, no specific orchitis will develop. According to my experience a safer procedure is to inoculate some mice with such a doubtful lesion. After four week's time these mice are killed, and an emulsion of their internal organs (liver, spleen) and lymph glands is inoculated into new rabbits. As mice are not susceptable to infection with $S$. cuniculi, a positive result in the rabbits inoculated with the mouse tissue-a syphilitic orchitis or a scrotal chancre-is thus evidence that the doubtful affection must have been caused by S. pallida.

In this connection may be mentioned a method which was described by Schereschewsky and used by this author and myself before the experiments of Nichols and Walker ; it made use of the spontaneous spirochetosis (S. cuniculi) of rabbits. As this disease could be transmitted by copulation, Ioo per cent. of positive infections being obtained if the genital parts of the healthy partner were scarified before the copulation, the method seemed to offer rather ideal possibilities of imitating the natural mode of infection. Another method consisted in testing the prevention of an infection with $S$. cuniculi after inoculation by means of a glass capillary pipette, which also caused Ioo per cent. positive takes in unprotected animals. Important biological differences, however, between the spontaneous spirochetosis of rabbits and the experimental rabbit syphilis of human origin led to this method being abandoned in favour of those using scrotal infection of rabbits with experimental syphilis.

Another method, inaugurated in Germany after the last war, consisted in the prevention of the recurrens infection of mice (Papamarku, Manteufel and Zschucke, Russ and others). It was not approved by the experiments of Schereschewsky and Worms and was generally 


\section{PROPHYLAXIS OF SYPHILIS}

abandoned, chiefly because of the great biological differences between $S$. pallida and $S$. recurrens and the differences between the infections to which they give rise.

Kolle and Schlossberger and, independently of them, I myself found that mice can be successfully infected with syphilis which in these animals causes only latent infection. This discovery should have suggested at once the use of these animals in investigating the prophylaxis of syphilis, but, so far as I have been able to discover, it was not until I938 that experimental mousesyphilis was used for this purpose. In that year Bessemans, van Thielen and de Wilde tried to inoculate the genital parts of mice by rubbing this region with a piece of tissue containing $S$. pallida from a testicular syphiloma of a rabbit. But even in the controls the transfer of the lymph nodes into rabbits gave negative results. A second gland transfer from these rabbits was apparently not made. On account of the negative results in the control animals, Bessemans and colleagues abandoned this method. One could, of course, make use of the syphilitic infection of mice for such investigations by inoculating more deeply, but as one would always have to perform lymph node transfers from them into rabbits, no real advantage would be apparent in such a method.

Having reviewed the methods which have been employed in testing locally applied prophylactic chemical agents I may now state briefly the results which have been obtained with the most important preparations; here it must again be emphasised that only results obtained by experimental research work will be considered.

\section{Calomel}

In vitro. As mentioned above, Schereschewsky and Worms-in numerous experiments-could not see any immobilisation of $S$. pallida by $33 \frac{1}{3}$ per cent. calomel ointment when contact was made between slide and coverglass. Bessemans and his co-workers, however, reported an immobilisation of the spirochetes by 33 per cent. calomel ointment after 5 to 20 minutes.

On monkeys. The first experiments were made by Metchnikoff and Roux. These authors proved in many experiments that primary sores could be prevented in 


\section{BRITISH JOURNAL OF VENEREAL DISEASES}

apes if a $33 \frac{1}{3}$ per cent. calomel ointment in a base of lanoline was rubbed into the inoculated area up to $18 \frac{1}{2}$ hours after the inoculation. Neisser failed to prevent syphilis with a Io per cent. ointment, and Hügel and Schereschewsky, although they used a 33 per cent. ointment, were unable to confirm Metchnikoff's results. C. Siebert had negative results in four experiments when he applied a Io per cent. calomel ointment containing also 0.8 per cent. sodium chloride (I per cent.) ; in both cases the ointment was applied one hour after the inoculation. These experiments show therefore that only Metchnikoff and Roux were able to report favourable results with their high percentage calomel ointment in monkeys.

On rabbits. Nichols and Walker succeeded in protecting 15 rabbits inoculated in the way described above, when 30 per cent. calomel ointment, sometimes in a base of equal parts of lanoline and vaseline and sometimes in a combination of 65 parts of benzoated lard and 5 parts of white wax, was applied to both scarified scrotal areas, in a quantity of I gramme to each side, from one to seven hours after the inoculation. Transfers of lymph glands of the protected animals to new rabbits were negative in all these cases. Nichols and Walker's results as well as the possibility of infecting rabbits percutaneously with other strains than the Nichols' strain (Manteufel and Worms) induced me to examine the effect of the 30 per cent. calomel ointment by this method. The results were, generally speaking, the same, whether an ointment prepared in Washington or in Berlin was used, and similarly whether the base was a mixture of equal parts of lanoline and vaseline or the benzoated lardwhite wax mixture. The death rate from mercurial poisoning in the treated rabbits was higher in the animals treated with the calomel in the benzoated-lard and whitewax base. In 48 experiments on 48 rabbits I came to the conclusion that a real protection was uniformly possible by this means only if the agent was applied not later than 15 minutes after an inoculation if the scarification preceding the inoculation was deep, but up to 2 hours if it was only superficial and slight. Worse results were obtained by Zurhelle, but apparently this was attributable to the very strong injuries produced by his method of scarification. He had failures even if he applied the ointment immediately after the inoculation, I96 


\section{PROPHYLAXIS OF SYPHILIS}

and in further experiments 8 minutes after the infection. Bessemans and co-workers who used the very mild mode of conjunctival inoculation described above had much better results. In experiments carried out on eight animals which were treated one to six hours after the inoculation, only one infection (I2.5 per cent.) occurred; this was when the ointment was applied three hours after the inoculation. The ointment used in these experiments had the following formula: calomel, 33; anhydrous lanoline, 33; vaseline, 34. In controls treated with the lanoline and vaseline base of this ointment infection was prevented when the base was applied not later than one hour after the inoculation.

In Mahoney's experiments in which the uninjured preputial sac was inoculated the calomel ointment (" a freshly prepared calomel ointment compounded after the original formula of Metchnikoff ") prevented infection in all cases if applied one hour before the inoculation, and in all but one if applied one hour after it. Mahoney's paper does not mention how many animals were treated in each group. An important point in these experiments is the enormous amount of ointment used for each animal, 4 grammes. If the average weight of a rabbit is about $2 \mathrm{~kg}$., the corresponding amount for a man of $70 \mathrm{~kg}$. would be 140 grammes, or $4.93 \mathrm{oz}$. Mahoney was able to protect seven out of ten rabbits inoculated in the same way when 4 grammes of this ointment was applied one hour later to a denuded skin area far removed from the actual field of exposure. For the inunction an area of the back was selected from which the fur had been removed by means of a barium sulphate paste. In a second series in which, however, only three out of five control animals were infected and the virulence of the spirochetes was thus apparently lower, nine out of ten animals were "protected" in the same way. In further experiments Mahoney was able to protect animals by application of the ointment to the skin area of the back after the preputial sac had been exposed to the spirochete emulsion for as long as two to three hours; the number of animals which were used for these experiments is not stated. That the calomel ointment could protect these animals by a " systemic" action of the mercury is ali the more remarkable as in tissue of the control animals obtained three hours after the infection and stained by 


\section{BRITISH JOURNAL OF VENEREAL DISEASES}

the Warthin-Starry silver method the spirochetes were found to have migrated well into the mucosa. I may here refer briefly to experiments made by myself in which infection was prevented in three animals by dusting the inoculated area with calomel 30 minutes after the inoculation (checked in two cases by lymph gland transfers).

Combined examinations in vitro and in vivo were made by C. Siebert and published as early as IgIr. Siebert made an emulsion of the organs of infected monkeys to which he added calomel powder in an amount of ro per cent. The emulsion was well triturated in a mortar, and I5 minutes later was inoculated into the eye-brow area of two series of four monkeys. None showed any syphilitic change. According to Siebert these favourable results were due to the conversion of the calomel into mercury perchloride through the action of the chlorides in the emulsion; also the strong concentration and the prolonged time in which the insoluble calomel transferred to the animal in the emulsion could act on the spirochetes.

As a supplement to this section on calomel may be mentioned Gauducheau's ointment, which was thought by its inventor to be an improvement on the old Metchnikoff cream. It contains thymol, $\mathrm{I} \cdot 75$; calomel, 25 ; lanoline, 50 ; vaseline, $23 \cdot \mathrm{I} 75$. The ointment is intended for use not only on the external skin, but also in the fossa navicularis where it is said to be non-irritant ; it is also said to be efficient against both syphilis and gonorrhœea. This ointment seems to have been tested on only a few animals. Gauducheau treated two out of four rabbits which were inoculated in the preputial area with the so-called neurotropic virus (S. cuniculi) after preliminary scarification. The two animals which were not treated and served as controls became infected, but the test animals showed no pathological change in an observation period of $4^{0}$ days. In vitro Bessemans and co-workers saw an immobilisation of the spirochetes by this ointment after ro to 30 minutes. Gauducheau himself examined the effect of his preparation in vitro by the following method. Two drops of the ointment and one drop of a suspension containing motile spirochetes were put together in a watch glass and well mixed, after which three or four drops of bouillon were added to the mixture, a specimen from which was now examined by dark ground 198 


\section{PROPHYLAXIS OF SYPHILIS}

microscopy. As a control, a similarly prepared broth dilution of the spirochetal suspension was used. All examinations were performed at a temperature of $28-30^{\circ}$. The result was immobilisation of spirochetes in the mixture containing the ointment and no change in the control mixtures. $S$. pallida as well as $S$. dentium were used for these examinations.

\section{Mercury Perchloride}

Plaut (I9IO) found that a solution of I in I,00o mercury perchloride immobilised $S$. pallida in five minutes, and Lee (I922) stated that it had the same effect within 20 minutes. Kolmer found I in I0,000 equally effective.

Extensive experiments on the action of solutions of corrosive sublimate in vitro and in vivo as well as only in vivo on S. pallida have been performed by C. Siebert. Solutions of the disinfectant were mixed with an organ emulsion from a syphilitic monkey for I5 minutes; after the greatest part of the liquid had been squeezed out of the organ emulsion the latter was inoculated into a monkey's forehead. As controls, apes were inoculated with the same emulsion which had not been mixed with the disinfectant solution. His experiments showed that the disinfectant action of pure solution of mercury perchloride was decreased by interaction of protein. Accordingly Siebert used solutions of mercury perchloride to which sodium chloride had been added. These did not precipitate protein, and penetration into the emulsion was made easier. Therefore, while solutions of mercury perchloride, I in Io,ooo, had no disinfectant effect on the emulsion, solutions of $I$ in I0,000 with sodium chloride were sufficiently effective. On the other hand, a solution of mercury perchloride, I in I0,000, mixed with blood had no effect on spirochetes, and even $I$ in 5,000 proved extremely unreliable.

Metchnikoff and Roux (I905) reported that a I in I,000 solution of mercury perchloride did not prevent the development of primary sores on a macacus cynomolgus although the inoculated areas had been washed with this solution for 4 minutes. The inoculation had been performed one hour before the application of the mercury perchloride. Three monkeys were inoculated by C. Siebert with syphilis in the region of both eyebrows. One hour 


\section{BRITISH JOURNAL OF VENEREAL DISEASES}

later these parts were treated with a solution of mercury perchloride, I in $I, O 0 C$, for two minutes; only one monkey escaped infection. In seven other experiments solutions of $I$ in 500 and $I$ in 300 proved effective. Siebert explained that the experiments in vivo required a stronger solution for a full disinfection than those in vitro because the action in vivo is much more difficult than in vitro where the duration of action, the concentration and the penetration of the disinfecting solutions are greater. In further experiments Siebert used the following solution: Mercury perchloride, 0.2 gramme ; Glycerine, 20.0 c.c. ; Distilled water, $80^{\circ} 0$ c.c. Five monkeys treated with this solution I5 minutes after the inoculation, three treated three hours after, one treated 6 hours after, and two treated 24 hours after escaped infection. Later Siebert recommended 0.4 per cent. mercury perchloride in a solution containing 25 per cent. alcohol and 25 per cent. glycerine. He believed that the disinfecting action of mercury perchloride was stronger in this medium than in a fatty one. The preparation was examined on II monkeys which were treated 5 to $I_{5}$ minutes after the inoculation. Of the II monkeys, 9 showed no pathological sign and 2 got doubtful primary sores. One of the monkeys was considered to have been unprotected because of the failure to reinfect it with syphilis. The value of reinoculation as a test of infection is, however, only limited. The Siebert preparation, which is called in Germany the Neisser-Siebertsche Schutzsalbe, had a strong immobilising effect on the spirochetes between slide and coverglass (Schereschewsky and Worms). I examined it in rabbits by means of percutaneous inoculation with the Nichols strain, and in these experiments it failed to prevent infection although it was applied in one animal 60 minutes before and 20 minutes after the inoculation, and in a second animal 33 minutes after the inoculation. Two more animals were protected 35 and 38 minutes after the inoculation (checked by lymph gland transfers), but all these experiments should be repeated and supplemented as they were too few for any conclusion to be drawn from them. I tested a simple solution of mercury perchloride in the same way. In 5 animals, I5 minutes after the perscrotal inoculation the inoculated region was washed with water and soap; 


\section{PROPHYLAXIS OF SYPHILIS}

and 4 were treated locally with a I/50o solution of mercury perchloride ; I animal, as a control, was locally treated with 70 per cent. alcohol. Of the first group, one animal died after two months without showing any syphilitic sign ; the three other rabbits remained healthy in an observation period of four to six months. From one of these animals a lymph gland was removed, and two passages were made without any positive result. The animal treated only with water, soap and alcohol developed a typical primary sore.

Also Zurhelle examined the prophylactic action of mercury perchloride in the form of an ointment containing I per cent. of the sublimate in a lanoline base. This did not prevent the development of primary sores even when it was applied immediately after a strong scarification-inoculation, but, as mentioned above, Zurhelle's way of testing by his strong scarifications is actually too severe. In view of his failures with mercury perchloride it is remarkable that Zurhelle should have succeeded after inoculation by his method in preventing infection by applying I per cent. mercury oxycyanide $\left(\mathrm{Hg}(\mathrm{CN})_{2}-\mathrm{HgO}\right)$ lanoline ointment, which I mention here also as a supplement to this section. Zurhelle seems to have been astonished himself at the fact that he did not obtain a single failure and admits therefore the possibility that these results were obtained only by chance. For these reasons Zurhelle continued testing this ointment and succeeded in protecting six further rabbits as checked by lymph gland transfers. Unfortunately in this later paper he does not describe exactly how he performed the scarifications. Ointments containing only 0.5 per cent. mercury oxycyanide had only a delaying effect on the development of the syphilitic changes, and those containing I per I,000 failed completely. It would really be worth while to examine the I per cent. ointment on a larger scale, as in human practice mercury oxycyanide is preferable to mercury perchloride because it is less injurious to the skin and mucous membranes.

\section{Bisulphate of Quinine and Mercury}

A German preparation called Dublosan contains $2 \frac{1}{2}$ per cent. bisulphate of quinine and mercury. It is said to be effective against gonorrhœa as well as syphilis. I 


\section{BRITISH JOURNAL OF VENEREAL DISEASES}

examined it for prevention of experimental rabbit syphilis (Nichols' strain). If it was used I5 minutes before and after the inoculation ( 3 animals), it was successful, and similarly when it was applied only 25 minutes before the inoculation (3 animals, checked in two cases by lymph gland transfers, partly in two passages), but an application only I 5 minutes after the inoculation was unsuccessful (3 animals). In this latter respect it proved therefore inferior to 30 per cent. calomel ointment. Also Zurhelle examined Dublosan, but got only bad results whether he used his weak or his strong scarification method for the inoculation. A further examination, however, of Dublosan on a larger scale may be worth while.

\section{QUININE HYDROCHLORIDE}

Siebert examined quinine hydrochloride solutions. In his examinations in vitro and in vivo a solution of $0 \cdot 2$ per cent. quinine hydrochloride acting on the organ emulsion for 15 minutes did not disinfect it so that four monkeys inoculated with the mixture were infected. In the same way with a 0.5 per cent. solution the protection was not reliable since only one of four monkeys escaped, two were infected, and in one the result was doubtful. Only a I per cent. solution protected all four monkeys of a further series. Comparing the action of quinine with that of sublimate, Siebert came to the conclusion that quinine was inferior. - In his experiments to disinfect monkeys with quinine I5 minutes after the inoculation, a solution of quinine 10.0 gramme with glycerine 80 c.c. and distilled water Io c.c. protected all four monkeys. This experiment confirmed former investigations by Schereschewsky and by Hügel.

In these a syphilitic papule excised from a patient was halved. One half was put into a ro per cent. solution of quinine hydrochloride for Io minutes and was then inoculated into the left eyebrow region, while the other half served for the inoculation of the right side. On this side a typical chancre developed; on the left side no syphilitic change was seen. Later Schereschewsky prepared a 40 per cent. quinine hydrochloride ointment in a base of anhydrous lanoline, $40^{\circ} \mathrm{O}$, and pure glycerine, 20.0 . After inoculations of both eyebrow regions of monkeys he applied the ointment to the left ; the time 


\section{PROPHYLAXIS OF SYPHILIS}

interval after the inoculation was ro minutes in three cases, and 25-30 minutes in two. In all cases the left eyebrows remained free, while on the most distant parts of the right sides primary sores developed. In a further 30 experiments carried out on monkeys in the same way the ointment was effective when it was applied even 5 hours after the inoculation. A weak point, however, in all these experiments, as already stated, is that in this method (test and control in the same monkey), it cannot be stated whether the infection has been prevented or only the primary sore suppressed.

After the last war, Schereschewsky, as well as Schereschewsky and Worms, examined the 40 per cent. quinine ointment by the methods described above (I) between slide and coverglass, (2) in its action on a syphiloma for 24 hours, and (3) in the prevention of the infection of spontaneous spirochetosis of rabbits. In all these experiments the quinine ointment gave splendid results. All the more surprising were the bad results which I found later when I examined this ointment in experimental rabbit syphilis. In 2 I experiments in which the inoculation was made with strong scarifications the ointment had no less than I7 failures in rabbits inoculated with the Nichols, or with the R.G.A., or with another strain. These failures occurred when the ointment was applied from I5 minutes up to 2 hours and I2 minutes after the inoculation. Also Zurhelle got very bad results in his experiments with $33 \frac{1}{3}$ per cent. quinine ointment, but his strong scarification-inoculation of the rabbit's scrotal region is, as repeatedly stated above, apparently too severe a procedure.

Better results were obtained by myself when I inoculated the rabbits only after a superficial scarification. In 2 animals a real protection-checked by gland transfers in two passages-resulted when the ointment was applied I5 to I7 minutes after the inoculation. In two further experiments I hour after inoculation on such a mild scarification the quinine ointment prophylaxis was also successful, and this result was confirmed partly by separate transfers of glands and internal organs as well as partly by a collective transfer of several lymph glands and the testes in two passages. The efficiency of the quinine ointment in preventing infection after weak scarification seems to extend up to 2 hours, as three 
animals treated in this way did not show any primary sore, and the control transfer of internal organs and lymph glands from two of them gave negative results. In spite of these favourable experiences after weak scarification it must be concluded that the quinine ointment is far inferior to the 30 per cent. calomel ointment as only the latter of these two prevented the infection when applied I5 minutes after inoculation on a deep scarification. The superiority of calomel ointment was confirmed by Bessemans, van Thielen and de Wilde, who also had worse results with the 40 per cent. quinine ointment.

I do not think it is necessary in this paper to deal with all the other chemical prophylactic preparations for local application, as the chief interest to-day is still concentrated in the practical use of Metchnikoff's calomel ointment and other mercurial preparations. Considering all the experimental work one is bound to say that so far the best results have been obtained in prophylaxis of experimental syphilis with the old Metchnikoff's calomel ointment. Two chemical substances, however, must also be mentioned; they are arsphenamine and related bodies and bismuth.

\section{ARSPhenamine}

It seems curious that experiments on the use of arsphenamine and related substances in prophylaxis by local application have hardly ever been made. This may be due to the observations by Plaut (IgIo), Truffi and Sabbia (I9II) and Lee (I922) who were unable to discover any influence of these substances on S. pallida in vitro. Truffi and Sabbia saw, however, prompt immobilisation of $S$. pallida, when they added to a mixture of arsphenamine solution and spirochetes a bit of spleen, adrenal capsule, or in particular liver. I myself (I926) investigated the action of a 20 per cent. neosalvarsan-glycerine solution and of a corresponding solution of Albert I02. The neosalvarsan, if applied 25 minutes before the inoculation, protected only two out of three rabbits from the infection; Albert ro2 was successful in two out of two animals when applied 30 minutes before the inoculation but was unsuccessful in one out of two rabbits when applied only 55 minutes after it. These experiments are, 


\section{PROPHYLAXIS OF SYPHILIS}

however, too few for any conclusion to be drawn from them, and a repetition seems to me all the more important and promising, since the work of Kolmer (1926), and of Kast, Peterson and Kolmer (I939), as well as that of Eagle (I938 and I939), has shown that even in high dilutions the arsphenamine preparations have a powerful immobilising effect on $S$. pallida and that intratesticular and intravenous injections of mixtures of these solutions and spirochetal suspensions did not infect rabbits. As it seems to me important for further deductions in this paper I may quote a passage in Kast, Peterson and Kolmer's paper as follows: "both compounds " (disodium arsphenamine and neoarsphenamine) " in final dilutions of at least $I: 20,480$ in citrated rabbit blood were completely treponemicidal after an exposure of ${ }_{5}$ minutes at room temperature. This final dilution carries $0 \cdot I$ c.c. of $\mathrm{I}: \mathrm{I}, 024$ of compound equivalent to about $0 \cdot 000 \mathrm{I} \mathrm{gm}$. and, since this amount was injected into each testicle, corresponded to a total of $0.0002 \mathrm{gm}$. But since the minimum single curative dose of arsphenamine in acute testicular syphilis of rabbits is about 0.010 to 0.0I2 gm, per kilogram and of neoarsphenamine about 0.020 gr., it is apparent that the actual amounts injected intratesticularly in the I: 20,480 dilutions were so far below [my italics] the therapeutic threshold as to leave no reasonable doubt but that the treponemicidal effects were those essentially produced in vitro." This conformity between the results in vitro and in vivo is rather surprising, but may be explained by the fact that the conditions in a free mixture of the chemical agent and $S$. pallida may be different from those prevailing between slide and coverglass.

\section{BISMUTH}

After having discovered the therapeutic action of bismuth on syphilis Sazerac and Levaditi examined also the question whether an ointment composed of sodium potassium tartrate of bismuth $30^{\circ} 0$; vaseline, and lanoline of each $30 \cdot 0$, could prevent the infection of rabbits which they had inoculated with the neurotropic virus $(=S$. cuniculi). They applied the ointment to six animals I, 4 and 24 hours respectively after the inoculation. Four of the six rabbits escaped infection in a period of observation of 50 to 94 days. 


\section{BRITISH JOURNAL OF VENEREAL DISEASES}

They had been treated I to 4 hours after the inoculation. The control animals developed lesions 20 and 22 days after the inoculation. The preventive effect of bismuth ointments should be tested again in experimental rabbit syphilis and on a larger scale. Such experiments seem to be more promising now since both Kolmer and Eagle found that bismuth has a direct action on S. pallida.

\section{Discussion and Suggested Lines of Further RESEARCH}

It would be most desirable to get more uniform results in further examinations. The reasons for so many differences in results by different workers appear to lie in the following: (I) The varying intensity of the mechanical injury preceding the inoculation. (2) The size of the injured area, which may also be important in regard to the speed and amount of the absorption of the chemical substance. (3) The region chosen for the inoculation-the best place seems to be the scrotum of the rabbit. (4) The amount of the chemical substance used. (5) Perhaps also the age of the ointments used and further, how long and how intensively they are applied. (6) The relative scarcity of the experiments made ; only large series of animals could eliminate errors due to chance which may play a part in any experiment.

Further studies on the action of mercury in the prevention of syphilis seen: to be necessary if, besides the local action, a systemic one occurs, as Mahoney believes. Another point worth investigation seems to be whether or not mercury could be found in the regional glands after the application of, e.g., Metchnikoff's calomel ointment, and if so after what length of time. In this connection I may refer to experiments by Süssmann on cats, in the scapular lymph glands of which mercury could be detected by chemical analysis after an inunction treatment of an area on the back with unguentum hydrargyrum cinereum.

Again, it would be interesting and of practical importance to know if inguinal lymph nodes excised from control animals as well as from animals treated with calomel ointment at various times after the inoculation were infectious for new rabbits when transferred to them at intervals a few minutes up to several hours after the 206 


\section{PROPHYLAXIS OF SYPHILIS}

inoculation or the application of the ointment. Kolle and Evers found that the inguinal lymph nodes of rabbits contained virulent spirochetes as early as 30 minutes after per- and subscrotal inoculations and that lymph glands of guinea-pigs contained $S$. pallida already 5 minutes after a percutaneous inoculation. Levaditi, Lépine and Vaisman were unable to confirm the results of Kolle and Evers. They could not find the syphilitic organism in the inguinal and popliteal lymph nodes of rabbits excised Io, 30 and 60 minutes after perscrotal or subscrotal inoculation. Bessemans and de Potter investigated the invasion of the inguinal and popliteal glands in a great number of rabbits which were examined from I 5 minutes up to 30 days after perscrotal and intratesticular inoculations. The popliteal lymph nodes of intratesticularly as well as those of perscrotally inoculated rabbits were found free of spirochetes 20,60 , I20 and I80 minutes, I7 and 24 hours and 3, 8 and I5 days after the inoculation. Positive results were not obtained until 30 days after the inoculation and later. The inguinal nodes of perscrotally inoculated rabbits-in which we are chiefly interested in this paper-did not contain spirochetes I5 minutes after the inoculation (one animal), but they were found in the glands of one out of two animals inoculated 30 minutes earlier and similarly in the glands of one of two rabbits inoculated 60 minutes earlier. In a further rabbit spirochetes were not found in these glands three hours after the inoculation. Tani, Ogiuti, Hutaki and Oya found spirochetes in the inguinal lymph nodes of perscrotally inoculated rabbits as follows: After 5 minutes in one out of two animals; after 15 minutes in two out of two ; and after 30 and 60 minutes in two out of two rabbits. They were even able to get a positive result in one out of two rabbits when they injected into a new rabbit the blood of one which had been perscrotally inoculated 5 minutes previously. This result corresponds somewhat to an observation made by Raiziss and Severac, who in the same way were able to show that the blood of an intratesticularly inoculated rabbit contained spirochetes as soon as 5 minutes after the infection. The above results show that the invasion of the lymph glands after inoculation is by no means invariable ; nevertheless all these observations may give the impression that the prospects of the local prophylaxis of syphilis by chemical 
agents are rather gloomy. But apart from the fact that early invasion of lymph glands and the blood need not be the rule, there is also the possibility that, on the one hand, the mercury may enter the lymph nodes and act there against the spirochetes (Worms, Gauducheau) or that spirochetes damaged by the local disinfectant might die in the lymph glands or in the blood, and on the other hand, that there may be a general systemic action of mercury which has been applied locally for prophylactic purposes.

The numerous experiments in which calomel ointment prevented infection of animals require explanation! If Mahoney's hypothesis of a systemic action of mercury is confirmed, it will show that the early invasion of lymph nodes does not necessarily render useless the application of local disinfectants, as Kolle and Evers believed. Support of Mahoney's findings is contained in the work of Albrecht and Evers who were able (1925) to bring about the disappearance of $S$. pallida in the primary sores of rabbits on the $5^{\text {th }}$ day after a therapeutic inunction of the abdominal skin with $\mathrm{I} \cdot 5$ gramme and larger doses of unguentum hydrargyrum cinereum, which contains $33 \frac{1}{3}$ per cent. mercury. In the same connection may be quoted experiments by Levaditi, Vaisman and Manin. These authors found that a smaller amount of novarsenobenzol was necessary to cure the rabbits in the incubation stage than when the primary sore was established. Here reference may again be made to the results of Kast, Peterson and Kolmer. It seems unlikely, however, that mercury could behave like novarseno-benzol in this respect. On the contrary-apart from the bad results Neisser as well as Uhlenhuth and Weidanz had with mercury-Tomasczewsky found that the development of a syphilitic keratitis in rabbits could be prevented by injections of corrosive sublimate during the incubation time only if the animals received a dose corresponding to eight or ten times the usual therapeutic dose for man. These results support the observations of Mahoney who used enormous amounts of calomel ointment, and the prophylactic effect of a systemic action of mercury does not seem out of question. But further and detailed research work is still necessary to clear up this and other problems connected with the prophylaxis of syphilis by locally applied agents. 


\section{PROPHYLAXIS OF SYPHILIS}

I am greatly indebted to Colonel Harrison for his most valuable and kind help in reviewing and correcting the text of this paper.

\section{REFERENCES}

Albrecht, B. and Evers, E. (I925) Med. Klinik., 21, I807.

Bessemans, A. and De Potter, Fr. (1933) Bull. Acad. Méd., 109, 908. Bessemans, A., van Thielen, E. and De Wilde, H. (I938) Bull. Acad. Méd. Belg., 3, 409.

Ditthorn, F. and Neumark, E. (I923) Z. Hyg. Infekt Kr., 100, I70.

EAGLE, H. (I938) Journ. Pharmacol., 64, I64 ; (I938) Johns Hopk. Bull., 63, 305 ; (1939) Amer. J. Syph., 23, 3II.

Esquier, A. (I936) Bull. Soc. franç. Derm. Syph., 43, II73.

Gauducheau, A. (I92I) Rev. Hyg., Police sanit., 43, 822 and 858.

HüGEL, G. (I908) Ann. Mal. vénér., 3, 737.

Kast, Cl. C., Peterson, Ch. W. and Kolmer, J. A. (ig39) Amer. J. Syph., 23, 150.

Kolle, W. and Evers, E. (I926) Dtsch. med. Wschr., 52, 1075.

Kolle, W. and Schlossberger, H. (I926) Dtsch. med. Wschr., 52, I245. Kolmer, J. A. (I926) "'Principles and Practice of Chemotherapy with Special Reference to the Specific and General Treatment of Syphilis." Philadelphia, W. B. Saunders \& Co., I926.

Lee, D. C. (I922) Amer. J. Syph., 6, 546.

Levaditi, C., Lépine, P. and Vaisman, A. (I932) Pr. méd., 40, 265.

Levaditi, C., Vaisman, A. and Manin, Y. (I938) Schweiz. Z. allgem.

Mahoney, J. F. (I936) Milit. Surg., 78, 35I. Path. Bakt., 1, I21.

Manteufel, P. (I922) Z. Hyg. InfektKr., 96, 387.

Manteufel, P. and Worms, W. (I925) Arch. Schiffs-u. Tropenhyg., 29,

Beiheft I, 225; (r928) Handbuch d. Haut-u.

GeschlKr. (J. Springer, Berlin), 18, 94I.

Manteufel, P. and Zschucke, H. (I92I) Dtsch. med. Wschr., 37, I947. Metchnikoff, El. (I906) Med. Klinik., 2, 37I.

Metchnikoff, El. and Roux, E. (I905) Ann. Inst. Pasteur., 19, 673 ; (I906) Bull. Acad. Méd. Paris, ze Série 55, 554.

Neisser, A. (I9II) Arb. ReichsgesundhAmt., 37, 248.

Papamarku, P. (I920) Dtsch. med. Wschr., 46, I847.

Plaut, H. C. (IgIo) Dtsch. med. Wschr., 36, 2237.

Raiziss, G. W. and Severac, M. (I937) Arch. Derm., 35, IIor.

Russ, V. (1922) Wien. med. Wschr., 72, I283.

Sazerac, R. and Levaditi, C. (I922) C. R. Acad. Sci. 174, I28.

Schereschewsky, J. (Ig08) Zbl. Bakt. I. Orig., 47, 4I ; (I9I I) Arb. ReichsgesundhAmt, 37, 566 ; (1913) Dtsch. med. Wschr., 39, I310.

ScherescheWsky, J. and WorMS; W. (I92I) Dtsch. med. Wschr., 47, I76 ; (I92I) Derm. Z., 33, Io ; (I922) Deutsch. med. Wschr., 48, 526.

Siebert, C. (IgII) Arb. ReichsgesundhAmt, 37, 530.

Süssmann, Ph. (I92I) Arch. Hyg., Berl., 90, 175.

TANi, T., Ôgiuti, K., Hutaki, H. and OYy, I. (I935) Zbl. Bakt. I. Orig., 134, 54 . 


\section{BRITISH JOURNAL OF VENEREAL DISEASES}

Tomasczewski (I9Io) Dtsch. med. Wschr., 36, 653.

Truffi, M. and Sabbia, U. (I9II) Pathologica., 3, 642.

Uhlenhuth, P. and Weidanz, O. (I908) Dtsch. med. Wschr., 34, 86 .

Worms, W. (I92I) Berl. klin. Wschr., 58, Iro3 and II64; (I923) Med. Klinik., 19, 1330 ; (1923) Zbl. Haut. u. Geschlkr., 9, 273 ; (1925) ibid., 17, 821; (1925) ibid., 18, 507; (I926) Arch. Derm. Syph., 151, 33I ; (I926) Dtsch. med. Wschr., 52, 785; (I927) ibid., 53, 959; (I927) Zbl. Bakt. I. Orig. Beiheft 104, 239; (I928) Derm. Wschr., 87, I9I6 ; (I929) Zbl. Bakt. I. Orig., 114, 356 ; (1930) Handb. d. path. Mikroorg. Kolle, Kraus, Uhlenhuth, G. Fischer u. Urban u, Schwarzenberg Jena, Berlin u. Wien., VII, 7I7 ; (1930) VIII Congr. internat. d. Dermat. et d. Syph. Copenhague 297.

Zurhelle, E. (I930) Dtsch. med. Wschr., 56, 7 ; (I930) VIII Congr. internat. d. Dermat. et d. Syph. Copenhague 992. 